\title{
VISUAL PERCEPTION SPECIFICS OF CHILDREN WITH ASD AS A DETERMINANT FOR EDUCATIONAL ENVIRONMENT OUTLINETIMES
}

\author{
Dr. Tatiana Bystrova, Ural Federal University, Yekaterinburg, Russia, E-mail: taby27@yandex.ru \\ Dr. Ludmila Tokarskaya, Ural Federal University, Yekaterinburg, Russia, E-mail: liydmil@mail.ru \\ Dr. Darko B.Vukovic, Perm National Research Polytechnic University, Perm, Russia \& Geographical Institute \\ Jovan Cvijic of Serbian Academy of Sciences and Arts, Belgrade, E-mail: vdarko@hotmail.rs
}

\author{
A R T I C L E I N F O \\ Original Research \\ Received: April, 12.2017. \\ Revised: Jun, 06.2017. \\ Accepted: Jun, 09.2017. \\ doi:10.5937/IJCRSEE1701075B \\ UDK \\ 37.035.6-057.875 \\ $172.12 / .15-057.875$
}

\section{Keywords:}

autism spectrum disorder,

visual perception,

image,

learning and teaching materials,

learning environment,

design.

\begin{abstract}
A B S T R A C T
The idea of inclusive education raises the question of security of children with autism spectrum disorders (ASD). It is the imperative of the time to create teaching materials that promote the effective implementation of educational curriculum. However, we have to stress the fact that most of the evaluable nowadays teaching materials have been created spontaneously, without any reliable criteria. Our primary hypothesis is that children with ASD have specific features of visual perception that do not depend on the state of their intelligence, which is confirmed by empirical data obtained by the authors. Our secondary hypothesis, specified in the process of research, stipulates that children with ASD will differently perceive different graphic images executed in different styles. These findings are further confirmed by empirical data collected by the authors in the study of perception and understanding of different graphic images by children with ASD and mental retardation. On the basis of theoretical and empirical data we specified the criteria for graphic design products which play a pivotal role in the formation of school educational environment. In this respect we focus on the criteria for design materials (including design criteria provisions, formulated by Norman, which he addressed to practicing designers).
\end{abstract}

(C) 2017 IJCRSEE. All rights reserved.

\begin{abstract}
"Humanity is going blind, accepting at "word value" the whole visible world, the mankind forgets to fully comprehend the messages coming through their eyes... The child, due to some preserved atavism, is still able to perceive the "strangeness", "difference" of world items. However, when the child makes the first step to school, this preserved atavism is replaced ulation of life"
\end{abstract}

Kuzma Petrov-Vodkin, Russian painter. 1917.

\section{INTRODUCTION}

Autism spectrum disorders are defined as a group of disorders that hamper the normal human interaction with the surrounding environment. More recently, autism was considered an extremely rare disorder: it was diagnosed in one child out of 20 thousand

\footnotetext{
Corresponding Author

Dr. Tatiana Bystrova, Ural Federal University,

Yekaterinburg, Russia,

E-mail: taby27@yandex.ru
}

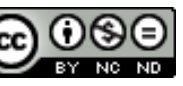

This work is licensed under a Creative Commons Attribution - NonCommercial - NoDerivs 4.0. The article is published with Open Access at www.ijcrsee.com
(Ivanov et al. 2004). However, since the mid1990s the number of such children has been increasing rapidly and today the ASD rate is close to $1.5 \%$, and according to some sources currently ASD occurs in 1 out of 68 children (Kim et al. 2011).

Children with ASD have pronounced peculiarities of communicative sphere, as well as stereotyped behavior with limited inclinations and interests and difficulties of social interaction (Nikol'skaya et al. 2010). In addition, one of the characteristic features of this category of children is the specificity of visual perception and understanding of the world, which, of course, should be taken into account in the organization of their learning process. The answer to the question of how 
these children understand the world around us, how they interpret incoming signals, will help create special manuals for them, resulting in contribution to their more successful learning and facilitation the work of the teacher. This makes the current scientific-developed approach to the design of textbooks, manuals, educational games a principal determining factor. Meanwhile, the problems of vision and control of communications of children with ASD are studied insufficiently. These problems are important both in terms of cognitive processes in general and specific practical recommendations for designers of educational and methodological materials (Bystrova and Tokarskaya, 2016a, 2016b).

Our findings cannot be regarded as complete. We've accumulated and processed special psychological data regarding the perception and communication of people with ASD. These data were confirmed by preliminary empirical research, which defined evaluation criteria and conceptual parameters of the final product. Consequently, generally submitted data will allow designers, who often work spontaneously, implying associations or observations without any regular sufficient scientific evidence, to identify specific criteria and means of expression. It is necessary to overcome the subjectivity and arbitrariness of design, because design is able to compensate a person with ASD many things that he/she cannot actively take from life.

Eventually in the article we put forward two hypothesis, the first one is that children with ASD have specific features of visual perception that do not depend on the state of their intelligence, which is confirmed by empirical data obtained by the authors. And the second hypothesis, specified in the process of research, stipulates that children with ASD will differently perceive different graphic images executed in different styles.

\section{MATERIALS AND METHODS}

The study is based on a cognitive approach (Anderson 2002; Kant 2015), considering the cognitive processes and mechanisms of knowledge acquisition as information processes, as well as a central element of active human psyche. Despite the lack of consensus among Western cognitive scholars (Lindsay and Norman, 1974) and Russian experts (Gal'perin 1999; Leont'ev 1959; Rubinstein 2002) on the question, regarding the essence of cognitive processes, we isolate a number of important propositions, which further may be projected into a picture of the mental life of a child with ASD. We find it necessary here to stem from the following propositions.

- The decisive role in cognition, including cognitive processes in education, belongs to active person's actions in addressing certain issues or problems (Kant 2015; Kelly 2000a; Anokhin 1971; Naysser 1981; Allakhverdov 2000). Automatisms and repetitions are not as effective as the active person's actions. This thesis gives us an epistemological foundation for the problem formulation about visual images' interpretation in front of the children, whose development we are interested in. Automatism simultaneously decreases heuristic value of the data by means of simple repetitive actions of the child.

- A person's ability to process stages (Luriya 2011) and synthesize data about the world obtained through knowledge, is based on his/her past experience (Solso, 2006). Psychic unit of information is stored in long-term memory and controls individual actions. This unit is packed into a frame, which we define as an integral individual stage of reality, connected by a system of "addresses" and "links" with other frames (see connectionism theory, proposed by Siemens 2008; Downs et al. 2004). The isolation of these frames in the analysis of multiple images gives an idea about the known or dominant structures that become the basis for the development of visual images for learning and teaching materials.

- The ability to explore and even measure these processes is based on the analysis of psychophysiological, neurophysiological processes (Tulmin 1984; Donald Norman 2002; Naysser 1981; Anokhin 1971; Bernstein 2000; Zabrodin and Lebedev 1977). This position makes it necessary to use psychophysiological tools, such as the eye tracker in post-project analysis of graphic materials that we plan in the future.

Substantial assistance in the investigation of the issue was found in the papers by psychologists and cognitive scientists, designers and practitioners of visual perception (Itten 2011; Zinchenko 1997; Rauschenbach 2002). It should be noted that Russian psychology offers less rigid disciplinary boundaries, leading to a greater variety of versions of cognition within the cognitive approach.

The closest to us, in terms of further practical application, are the representative cognitive approach ideas in design, formulated by the American theorist Donald Norman $(2002,2013)$. In particular, Norman and 
Norman (1988) introduced such indicators of cognition, based on human design, as the information content / clarity / intuition; emotion, aesthetics (Norman, 2002). As specified in the empirical studies of visual processes of children with ASD, these characteristics may further be developed into the criteria for professional evaluating of design products.

In this paper we, firstly, analyzed the features of the interaction of children with ASD with the environment and other people, including the visual perception parameters, we derive from the primary design criteria. Secondly, we conducted the research of perception features and understanding of a variety of graphic products for children with ASD and mental retardation. In view of these data, we formulate recommendations for graphics products. All this is necessary to create a pilot version of a special graphical educational product for children with ASD, as well as its testing and adjustments in the Ural Federal University (Ekaterinburg, Russia).

\section{RESULTS AND DISCUSSION}

\subsection{Results}

Eventually, proceeding from the results of the study, we assume that visual perception of children with ASD is more influenced not by their intellectual level, but, above all, by the severity of their autistic features, what explains the similarity of received results with the results of other researchers.

We offer a number of recommendations for the design of manuals for children with ASD:

1. The "conceptual model" (Norman 2006) of a specific product should take into account the cognitive features and models of interaction with the subject, typical of children with ASD. Designers have to move away from publishing standards. "A good conceptual model is the line between the right and wrong use of many things" (Norman 2013). For example, when fixing unintentional vandal actions against a book, it can be envisaged to make the book from more economical disposable materials. Another option that corresponds to Norman's idea of "perceiving purpose" is connected with distraction of the child's attention from unacceptable actions with respect to the projected object. It can be done again at the expense of texture, color, layout and design features.

2 . The understanding of the educational model for which a particular project is being implemented can be an essential aid for the designer. For example, L. Vygotsky's “developmental training" and the idea of social constructivism makes it possible to create a stylistic or image structure that is isomorphic to the structures of the life of a given individual or group of children in order to activate internal dialogue. They can be variably repeated when displaying different objects. Of course, in this case the designer cooperates with the teacher, and not only with the child.

3. The depicted object should be specific and realistic enough, but not necessarily highly detailed (insofar as it cannot be confused with something else - a cat with a fox or a squirrel, etc.). It is rather a question of the "coincidence of codes" (Anokhin 1971) of the artist and the perceiver. It is necessary for the child to catch the sense of the image in that short period of time when his attention is productive and does not bring a different meaning to the depicted subject. Stroking shapes and objects with a black line is one way to achieve greater clarity of the figure, relative to the background. More abstract symbols do not contribute to this, but this is still a hypothetical statement which has to be further tested separately.

4. The background plan should be executed as simply as possible, so as not to interfere with the perception of the main image. It can have a planar character and cannot contain elements that enhance the perspective effect.

5 . The color scale should not be necessarily obscure. If the depicted object is bright and by contrast stands out against the general background, it will contribute to the perception of the child. At the same time, one should take into account the possibility of rapid emotional overload of the child and, if necessary, obscure tones or "watercolor" tones can be given in bleached, background colors.

6 . The attention of the child is strengthened by the interest in the depicted object. This can be facilitated by textural, sound, aromatic and other inserts in the book, significantly increasing its production cost, which is sensible in special cases.

7. If the illustrations in the manual become embossed, the child will find it easier to focus on the information received and will take it more fully. The book should give an idea of the object so that as many sensory organs as possible can be activated, which will allow to achieve a polysensory effect.

8 . It is necessary to take into account the scenario of interaction with the object - both in cases of a child's individual work or the 
work with a tutor, teacher, parent, i.e. someone who activates the contact and pays attention to the individual elements of the image. The included observation shows that children with ASD often repeat movements of adults. This observation can be used in the development of such educational teaching materials, as handwriting manuals, primers, etc.

9. It is necessary to carry out postproject research of the publishing product using the method of focus groups, and further to correct the image, zooming on the more frequent reactions of children with ASD.

\subsection{Visual perception features of people with ASD}

In the scientific literature there are various, often conflicting data about the features of the processing of visual information by people with ASD. These data are very scattered and sometimes contradictory, so the first priority is their generalization and systematization.

A phenomenal ability to process visual information by people with ASD is exemplified in the description given by the American professor Temple Grandin (who herself is an adult woman having an autism spectrum disorder, whose autistic features she managed to overcome), “... My thinking is purely visual. ... I happened to design large and complex agricultural systems, but to remember a phone number or to add two numbers is a challenge for me. If I want to remember something abstract, I visualize it as if I "see" the information I need on a page from a book or a notebook and then "read it out" from there... To remember something heard, I need it to be emotionally loaded or connected with some visual image "(Grandin and Skariano, 1999, 221). However, this level of activity, even the dominance of visual thinking is not typical of all people with ASD, and it is unlikely that these data can be used for publishing design for children with ASD of all categories.

The variety of visual perceptions is further exemplified in the data by Lebedinskaya and Nikol'skaya. They call it "a look through the object", resulting from a lack of eye tracking of object, or "pseudo blindness". For ASD people it is necessary to focus their views on a "pointless" object: a light spot, a shiny surface area, a pattern of wallpaper, carpet, flashing shadows. Such people are spellbound with such contemplation. ... However, they exhibit early color discrimination, the interest in drawing stereotyped patterns" (Lebedins- kaya and Nikol'skaya, 1997, 119-120). Positive perception of simple patterns and ornamental fig-ures may suggest useful tricks for a graphic designer, who is doing the design of book surfaces, exercise books and other educational materials. However, it is important to clarify these ideas in the postproject analysis by means of interviews and focus groups surveys of users of such design products.

Thus, the visual culture (Zinchenko 1997) of people with ASD varies greatly. A number of circumstances have to be taken into consideration in connection with these ideas, i.e. a person with ASD may have a difficulty associated with the treatment, understanding and responding to information coming from the sensory organs. Symptoms of autism may include such features as a lack of eye contact, viewing luminous or moving objects, fleeting glances, a look to the side and a difficulty with a long eye contact, as well as sensory integration difficulties (Lebedinskaya and Nikol'skaya, 1997; Lebedinskaya 1997; Nikol'skaya et al. 2010; Lebedinskiy et al. 1990).

Many people with ASD are "visually defensive." A "visually defensive" person avoids contact with a particular visual information, and may be hypersensitive to it. Individuals with ASD have difficulty in retaining the look and often use continuous scanning of visual information in an attempt to understand its significance.

Since the visual system is related to the motor, cognitive and speech development, in case of violation of the visual information processing, some disorders may arise in these areas (The animals vacation, 1964).

It should be noted that children with ASD in their development are generally less attentive to the people, and many social interactions (Dawson et al. 1998; Dawson et al. 2004; Siemens, 2008). They are characterized by a rare or abnormal eye contact (Dawson et al. 1998; Sigman et al. 1986).

In connection with this thesis, we proceed to the description of the following experiment. Researchers at Caltech have shown 700 different pictures in three seconds. The scientists used a special device that reads eye movements, a fixed region on the picture, to which people paid attention. The right image shows the trajectory of view of persons with ASD, and the left - the view of "ordinary" people (Figure 1). The red zone which corresponds to the most viewed locations, shows that individuals with ASD focus their attention in the center of the frame. When they see a person, then look the other way (Eti izo- 
brazheniya pokazyvayut, kak autisty vidyat mir [These images show how autistics see the world]).

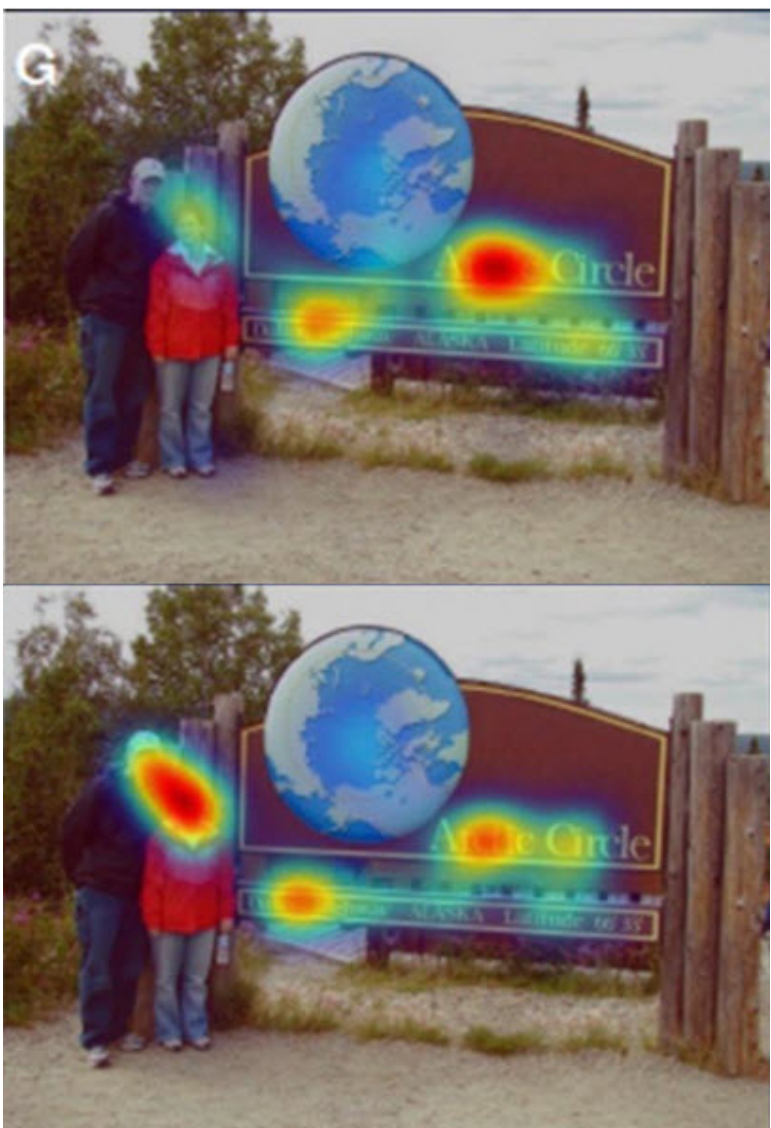

Figure 1. The trajectory of view of people with ASD in comparison to the look of "ordinary" people.

This point must be taken into account by designers to create any anthropomorphic products: portraits or images of people. They cannot "impose" a person with ASD a normal person's attention focus.

\subsection{Specific characteristics of visual perception of people with ASD (methods, research procedure and discussion)}

In this part of the paper wo proceed to the analysis of our own research results and the studies' results, obtained by Kostin (1997).

The need for our own study was dictated by the fact that "the majority of people with autism also have moderate or severe mental retardation (60\% of people with ASD have IQ level which is below 50) (Piters, 1999). There is a need to clarify the features of their visual perception. Of particular interest is the under- standing of children's vision of books, first of all, the images in books, for it is the essential basis for maintaining educational process at school.

Our study was conducted in October 2016. The aim of the research was the identification of universal criteria for illustrations' guidelines, which may be of assistance for special manuals targeting children with ASD. The study was conducted on the basis of the state educational institution of Sverdlovsk region Yekaterinburg school № 4. A total of 10 children, aged from 7 to 17 years, took part in the experiment. Among the participants there were 3 girls and 7 boys, among whom there were 3 nonspeaking children.

The study was conducted individually with each child; in the course of the experiment each child was given a set of technically different images. The selection of illustrations was based on the principle of maximum similarity of visual techniques used by people with ASD (the analysis was based on more than 100 images executed by people with ASD), as well as with the above mentioned features of perception and understanding. In the course of the experiment we developed a number of innovative approaches. For example, the knowledge of the "visually defensive" process led us to the idea to limit demonstration of pictures only to the pictures with images of full face and eyes, directed beyond the artistic reality. The understanding of the nature of ornament (Gerchuk, 1998) in comparison with the tendency of people with ASD to create simple patterns led us to use images that were mostly two-dimensional, rather than three-dimensional. "Gestalt" nature of perception and the "field dependence" demanded from us to select images with prominent large-scale central characters.

The illustrations were presented to children on a tablet. All images were divided into three groups which were as follows:

- the illustrations by G. Spirin (B сказочном царстве. Иллюстратор Геннадий Константинович Спирин [In the fairy-tale kingdom. The illustrator Gennadiy Konstantinovich Spirin]), carried out in the most realistic style, with a high degree of detail of the basic figure, but with the planar backgrounds devoid of prospects;

- the specially stylized illustrations with a tendency to planar painting by Vasnetsov (Виктор Михайлович Васнецов - биография и картины [Viktor Mikhailovich Vasnetsov biography and pictures]);

- other illustrations (the ones which chil- 
dren accidentally marked as recommended by teachers, etc.).

In the study, we encountered a number of difficulties in receiving feedback, namely:

- children with ASD were completely

different in the level of their involvement, as well as their response to the researcher, their interest in the study, which at times amounted to complete unwillingness to participate in the initial stages of research;

- some children were speechless, or observed the autonomy of speech (words were not connected with the research activity). In addition, many children slurred speech, put in echolalia, individual words, provided monosyllabic answers;

- some children were attracted just by the process of changing pages and flashing images, rather than viewing and discussing them;

- the tablet itself sometimes could become more attractive as an object of manipulation, rather than the images;

- we uncounted a number of difficulties in the diagnosis of children's visual preferences, as the children themselves did not express their emotional attitude to the presented figures, they did not indicate what they liked better;

- in the course of the study the children were often selfabsorbed, they were barely included in the experimental procedure;

- non-verbal children could only point at the object, which was recommended by the researcher. Such procedure skewed the results, as it was not known, whether the child would have outlined the items himself, if the item hadn't been recommended by the researcher;

- we faced errors in object naming due to the children's intelligence specifics: they called a castle a house, Thumbelina a doll, a balalaika a scraping;

- children did not describe the picture as a whole, they simply listed depicted items. They described the pictures in telegraphic style, i.e. "pig, house, smoke," "bear, night, three Christmas trees";

- children's attention was hard to get. Once attracted, it was quickly lost.

As a rule, while sequential viewing, the children called details of the image from top to bottom, however, the more common situation was when the children only named the main elements of the image. Often there was a sense that children did not watch the pictures carefully, they could only point out general ideas, generated from these figures.

In the study by Kostin (1997) there participated 9 males (13-20 years of age), the state of their intelligence was not specified.

Based on the results, there was an attempt to determine the features of a glance position in the design of objects related to the surrounding environment. Kostin (1997) described them as follows.

1) Low information resistance. From the birth a child with ASD has a difficulty with focusing on anything in particular (Что в душе аутиста, беседа с Ирис Йохансон [What is in the soul of an autist, a conversation with Iris Johanson]), or one person to create a natural atmosphere of contact. Therefore, "the one who wants to communicate with an autistic child, must increasingly focus his attention, to create this contact atmosphere" (Chermenskaya, 2014) (Figure 2).

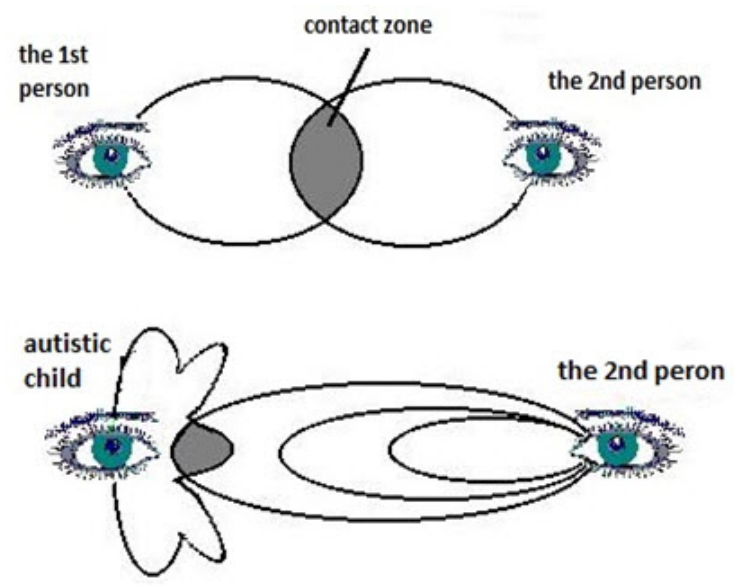

Figure 2. The diagram of communication of a "normal" person as distinct from people with ASD. Source: Chermenskaya, 2014.

Some of the people with ASD perceive other people only at the level of objects. The psychologist from the Institute of Health and Medical Research (France) M. Zilbovicius explains: "Because of genetic disorders, the brain of these children is excessively active. He just does not have time to connect, analyze everything that the child sees, hears, feels. The world is perceived in a fragmented and distorted way by him" (These images show how autistics see the world).

According to the data obtained in the course of our own research, children with ASD and mental retardation hardly concentrate on drawings. Such children can perceive people at the level of objects. According to our data, the process is aggravated, by the severity of intellectual disorders. Three out of ten children did not name the man on the balcony of the house (Figure 3), besides, there were difficulties in recognizing the image of Baba Yaga (Russian fairy monster old lady) in the illus- 
trations by G. Spirin (В сказочном царстве. Иллюстратор Геннадий Константинович Спирин [In the fairy-tale kingdom. The illustrator Gennadiy Konstantinovich Spirin]).

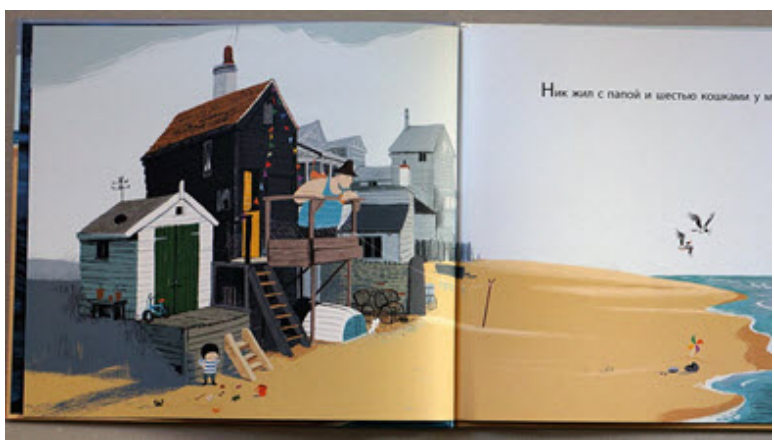

Figure 3. The illustration for the book "The Day, When the Whale Returned". The author and artist is B. Davis.

Field dependence". This is how Kostin (1997) denoted the difficulty of isolating individual elements in a composite image, as well as the semantic organization of the visual field. Two children with ASD and mental retardation demonstrated the same features.

This quality of visual perception of people with ASD should be taken into account by a designer when creating complex system products - books, workplaces, interiors. You either need to simplify the form, or create a clear, well-perceived structure, avoiding unnecessary detail. Another option is to set the sequence of special simple individual elements that together make up something more complex without losing the integrity of the image.

"Gestalt" perception, i.e. poorly articulated, insufficiently detailed style of perception. Researchers note that "it is difficult to figure out in detail that it consists of a lot of details, saturated with perceptual information and at the same time given without any obvious subject content". As a rule, it was difficult for them to figure out the concept of the drawing" (Kostin, 1997). So, in everyday life, a small change (for example, otherwise arranged furniture in a well-known room) can become a reason for an affective breakdown for a person with ASD. The undifferentiated representation is completely destroyed by the slightest change in details; subjectively, a person with ASD is in a completely new, unfamiliar situation.

Children with ASD and mental retardation saw a "tree" in the picture depicting Baba Yaga, yet, in the other picture, "Thumbelina sitting on a flower", children saw a "butterfly". Thus, even if the drawing is realistic, objects can be perceived as distorted if they are not clearly drawn.

Children with ASD and mental retardation (MR) almost do not pay any attention to background details, especially small ones. So, they spotted flying birds in the foreground, but the image of the lakes in the background were not noted. In another picture, only the central figure of the cat was marked by a child with ASD and MR, and other cats, shown on the right and along the perimeter, went left unnoticed, perhaps they seemed insignificant to the child with ASD and MR, or merged with the background. On the other hand, a rooster and a kitty, depicted along the perimeter of the picture, were carefully described. However, the central figure was left unattended. Noteworthy, that $40 \%$ of children managed to exhibit the ability to perceive both the background of images, including a reduced format, and performed the description with less accuracy (children counted houses, specified that there was snow in the street, etc.).

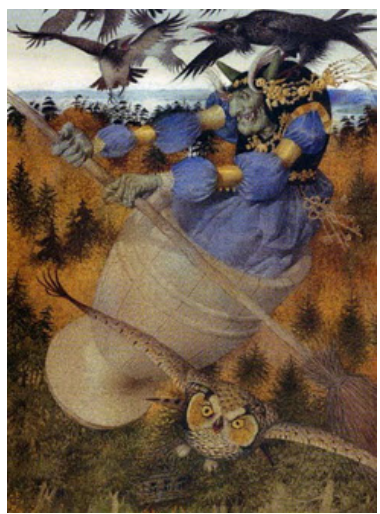

Figure 4. Baba Yaga. Illustration for the children's book. The artist is G. Spirin. http://vladmama.ru/forum/viewtopic. php? $\mathrm{f}=585 \& \mathrm{t}=202523$

This observation is especially significant when a person with ASD contacts dynamic images, including virtual images. Perhaps, the person generally denies them in training or sets very strict limits of their usage.

The difficulty of contact with a changing environment can be partially removed if, say, before the beginning of school classes a child with a ASD receives from a certain source (textbook, manual, book, manual) a visual image of the space in which he is to be. Correct graphic design is able to inform and prevent possible affective reactions.

Inflexibility, inertness of perceptual processes. The method of organizing the visual image, which the person with ASD designated to be the first one, as a rule, is rigidly 
imprinted in the consciousness and is hard to be changed. In everyday behavior of people with ASD, this leads to categorical views, a weak ability to take another point of view, the difficulty of changing one's behavior in accordance with the dynamics of the situation.

In the course of the study children with ASD and mental retardation made a lot of errors. For example, they called storks geese, which flew in jamb. They called dogs deer, who were harnessed to a team. The castle looked like Moscow (linked to the image of the Kremlin), they called a dwarf Santa Claus, and a cat $-\mathrm{a}$ wolf, a squirrel - $\mathrm{a}$ fox, a girl - a grandmother, etc.

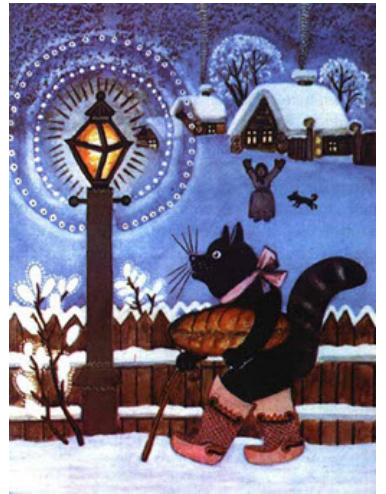

Figure 5. Koten'ka Kotok. Illustration in a children's book. Artist Y. Vasnetsov http://miryanin.narod.ru/vasnecov3.jpg

Undoubtedly, designers are mostly focused on new, original, innovative ideas. In the case of projects for people with ASD they will most likely have to moderate their craving for novelty, opposing it to some conservatism of solutions or introducing novelty in moderate doses. This is possible only if a designer has data about his target audience, conducting preliminary interviews and surveys.

The affectivity of perception - a process with the high dependence of intellectual productivity activity on the emotional state. This means that the visual field can be structured in a special way, led by affective behavior. Separate affect-charged islands ("figures") can be allocated in a more or less equal background. The latter are mostly often associated with the subject of affects, the stereotypical interests of the autistic personality. This attractiveness determines the two-tiered structure of the visual field: it contrasts the affectively charged figure that stands out on an emotionally neutral background.

Children with ASD and MR often showed reluctance to view pictures, if for this it was necessary to distract them from a meaningful task. It was necessary to get them interested in the activity. Perhaps, a picture depicting things that were important to children could cause more interest. All children watched with a bigger interest familiar, affectively relevant pictures, primarily related to an interesting for them activity.

Evidently the children with ASD and mental retardation liked the pictures made in a more realistic style (В сказочном царстве. Иллюстратор Геннадий Константинович Спирин [In the fairy-tale kingdom. The illustrator Gennadiy Konstantinovich Spirin]); children described these pictures better, noticed more details.

In the course of the study it was revealed that children with ASD had a more rapid perception of a number of details of images, in comparison with the average indicators of normal children. The difference is quite evident in case with the number of objects that the child named almost without thinking -16 .

In addition, it was found that some children with ASD can be assisted very closely by tactile contact. The child takes words better, if he is taken by the hand, stroked on the head. The teacher can some-how designate his presence at a tactile level, if the child does not mind it. The polysensory perception provides a better understanding of these activities by the children. This aspect can be taken into account in design of manuals for such children.

In addition, the organization of the visual field must be necessarily based on speech, verbal function (Kostin, 1997). Studies show that in the organization of the visual field, one can move towards a greater activity, integrity, improving, in the final analysis, the general adaptation of people with ASD. At the same time, as we assume, the effectiveness of work with perceptual material can be raised, if from the first years of life the child with ASD will be accompanied by the products of professionally tailored design.

\section{CONCLUSION}

The obtained data outlines the horizons of further psychological research of the visual perception of the people with ASD. Our findings confirm unusual parameters and criteria for evaluating the designer's work with products for people of this category.

There is a growing need for a holistic system description of the diversity of research in this field. Of much importance is the clarification of leading approaches to the design 
of quality didactic materials for children with ASD in inclusive educational space. Much attention should be given to psychological and social mechanisms, structural elements, aesthetics and stylistics of products, as well as their formats and functions.

At one of the initial stages it is necessary to determine the level of intuitive (D. Norman) and attractive images. A study on clarifying the features of understanding and adopting a particular style of visual materials for children with ASD can be continued with the help of special equipment, an eye tracker in particular.

In turn, this activity requires adequate project tools and helps not only develop the theory and practice of graphic design, but above all, makes the process of including children with ASD in the education system more successful.

\section{ACKNOWLEDGEMENTS}

This article was supported by the Act 211 Government of the Russian Federation, agreement № 02.A03.21.0006 and by the Ministry of Education and Science of the Republic of Serbia under Grant III47007.

\section{Conflict of interests}

Authors declare no conflict of interest.

\section{REFERENCES}

Allakhverdov, V. M. (2000). Consciousness as Paradox. Eksperimental'naia psikhologika, 1 .

Anderson, D. R. (2002). Cognitive psychology. SPb.: Piter.

Anokhin, P. K. (1971). Philosophical aspects of the theory of a functional system. Soviet Studies in Philosophy, 10(3), 269-276. http://www. tandfonline.com/doi/abs/10.2753/RSP106119671003269

Bernshteyn, S.B. (2000). On the problems of dialectology and linguogeography. "Indrik".

Bystrova, T.Y., Tokarskaya, L.V. (2016a). Graphic design for people with ASD. Akademicheskiy vestnik UralNII Proekt RAASSN, 2 (29), 95-99. Retrived from: https://elibrary.ru/download/elibrary 26279712 93314492.pdf

Bystrova, T.Y., Tokarskaya, L.V. (2016b). Designing an educational environment for children with autism spectrum disorders: the formulation of the question. Seriya 1. Problemy obrazovaniya, nauki i kul'tury, 1(47), 168-175. Retrived from: http://elar.urfu.ru/bitstream/10995/38070/1/ iurp-2016-147-22.pdf

Chermenskaya, G., (2014). How do people with autism see us. Psihologiya: lichnost', 3(3). Retrived from: http://www.psychologies.ru/self-knowledge/individuality/kakimi-nas-vidyat-autistyi2/
Chto $v$ dushe autista, beseda s Iris Yohanson [What is in the soul of an autist, a conversation with Iris Johanson].(2015). Retrived from: https://goo. $\mathrm{gl} / 8 \mathrm{DAPYO}$

Dawson, G., Meltzoff, A., Osterling, J., Rinaldi, J., Brown, E. (1998). Children with autism fail to orient to naturally occurring social stimuli, Journal of Autism and Developmental Disorders, 28(6), 479-485. Retrived from http://ilabs. washington.edu/meltzoff/pdf/98Dawson Meltzoff etal JADD.pdf

Dawson, G., Toth, K., Abbott, R. (2004). Early social attention impairments in autism: social orienting, joint attention and attention to distress. Developmental Psychology, 40(2), 271-283. doi:10.1037/0012-1649.40.2.271

Eti izobrazheniya pokazyvayut, kak autisty vidyat mir [These images show how autistics see the world]. Retrieved from https://econet.ua/articles/80959eti-izobrazheniya-pokazyvayut-kak-autistyvidyat-mir

Galperin, P. Y. (1999). Introduction to Psychology: Textbook for High Schools. (in Russian). Retrieved from http://pedlib.ru/Books/3/0297/3 0297-1. shtml

Gerchuk, Y.A. (1998). What is an ornament? The structure and meaning of the ornamental image. M: Galart.

Grandin, T., Skariano, M. (1999). Opening hope doors. My experience of overcoming autism. M: Tsentr lechebnoy pedagogiki.

Itten, I. (2011). The Art of Color. Izdatel' D. Aronov.

Ivanov, E., Dem'yanchuk, L., Dem'yanchuk, R. (2004). Children's Autism: Diagnosis and Correction. "Didaktika Plyus".

Kant, I. (2015). The Critique of Pure Reason. Eksmo, Moscow.

Kelli, D. (2000). The Theory of personality (Theory of personal constructs). SPb.: Rech'.

Kim, Y. S., Leventhal, B. L., Koh, Y. J., Fombonne, E., Laska, E., Lim, E. C., ... \& Song, D. H. (2011). Prevalence of autism spectrum disorders in a total population sample. American Journal of Psychiatry, 168(9), 904-912. Retrieved from https:// doi.org/10.1176/appi.ajp.2011.10101532

Kostin, I. (1997). Organization of perceptual information in adolescents and young men with autism. Defektologiya, 1 .

Lebedinskaya, K., Nikol'skaya, O. (1997). Diagnostic card. The study of the child of the first two years of life with the assumption that he had early childhood autism. SPb.: Mezhdunarodnyy universitet sem'i i rebenka im. R. Vallenberga, 116-123.

Lebedinskaya, K. (1997). Early Childhood Autism. $\mathrm{SPb}$.: Mezhdunarodnyy universitet sem'i i rebenka im R. Vallenberga, 77-91.

Lebedinskiy, V., Nikol'skaya, O., Baenskaya, E., Libling, M. (1990). Emotional disorders in childhood and their correction. Izd-vo Mosk. un-ta.

Leont'ev, A.N. (1959). Problems of development of the psyche. Izdatel'stvo Akademii pedagogicheskih nauk RSFSR.

Lindsey, P., Norman, D. (1974). Information processing in humans (Introduction to psychology). "MIR".

Luriya, A.R. (2011). A little book about big memory. Izdatel'stvo MGU.

Miller, G., Johnson-Laird, P. (1976). Language and perception. Cambridge, Mass.: Harvard University Press. 
(IJCRSEE) International Journal of Cognitive Research in Science, Engineering and Education Vol. 5, No.1, 2017.

Naysser, U. (1981). Cognition and Reality. Progress.

Nikol'skaya, O., Baenskaya, E., Libling, M. (2010). Autistic child: ways to help. Terevinf.

Norman, D., Norman, D.A. (1988). The Design of Everyday Things. New York: Basic Books. Strelka Press.

Norman, D. (2002). Emotion \& design: attractive things work better. interactions, 9(4), 36-42. http:// dl.acm.org/citation.cfm?id=543435

Norman, D. A. (2006). Emotionally centered design. interactions, 13(3), 53. https://interactions.acm. org/archive/view/may-june-2006/emotionallycentered-design 1

Norman, D. (2013). Things' design of the future. Strelka Press.

Piters, T. (1999). Autism: from theoretical understanding to pedagogical influence. Institut spetsial'noy pedagogiki i psihologii.

Raushenbah, B. (2002). The geometry of the picture and visual perception. $\mathrm{SPb} .:$ Azbuka-klassika.

Rubinshteyn, S. (2002). The Fundamentals of General Psychology. SPb.

Siemens, G. (2008). About: Description of connectivism. Connectivism: A learning theory for today's learner, website.

Sigman, M., Mundy, P., Sherman, T., \& Ungerer, J. (1986). Social interactions of autistic, mentally retarded and normal children and their caregivers. Journal of Child Psychology and Psychiatry, 27(5), 647-656. doi:10.1111/j.1469-7610.1986. tb00189.x

Solso, R. (2006). Cognitive psychology. SPb.: Piter.

The animals vacation (1964). Illustrated by Shel and Jan Haber, NY.

Tulmin, S. (1984). Human understanding. Progress.

In the fairy-tale kingdom. The illustrator Gennadiy Konstantinovich Spirin. https://vdohnovenie2. $\mathrm{ru} / \mathrm{v}$-skazochnom-carstve-illyustrator-gennadijspirin/

Viktor Mikhailovich Vasnetsov - biography and pictures. https://muzei-mira.com/biografia hudojnikov/765-viktor-mihaylovich-vasnecovbiografiya.html

Vygotskiy, L.S. (1996). Teachers' training psycology. Pedagogika.

Zabrodin, Y., Lebedev, A. (1977). Psychophysiology and psychophysics, Nauka.

Zinchenko, V. (1997). Image and Activity. Voronezh: NPO "MODEK". 